\title{
Using GIS Tools to Estimate Health Risk from Biomass Burning in Northern Thailand
}

\author{
By Borworn Mitmark* \\ Wanida Jinsart ${ }^{\dagger}$
}

\begin{abstract}
The assessment of adverse health effect from air pollutants exposure in the north of Thailand was studied. Eight provinces were in the risk areas from biomass burning pollutants which occurred in the dry season from January to April annually. The haze pollutants are from the burning of agricultural wastes to prepare for the next crops plantation in addition to natural forest fires. The pollutants such as, fine particulate matter $\left(P_{10}\right)$, carbon monoxide $(\mathrm{CO})$ and ozone $\left(\mathrm{O}_{3}\right)$ have adverse health effects to the resident and tourists in this area. Daily concentrations of three monitored air pollutants $\left(\mathrm{PM}_{10}, \mathrm{O}_{3}, \mathrm{CO}\right)$ during January 2011-December 2015 were provided by the Pollution control department in Thailand. Each individual was geo-coded in ArcGIS10.1 software. The spatial distribution of three pollutants and the temporalspatial specific air pollutants exposure level for each individual was estimated by the Inverse Distance Weighted (IDW) interpolation. The Hazard Quotient (HQ) of PM 10 , $\mathrm{CO}$ and $\mathrm{O}_{3}$ were calculated from the ratio of exposure concentration and reference concentration Hazard Indices $\left(\mathrm{HI}_{P M 10, \mathrm{CO}, \mathrm{O} 3}\right)$ are calculated from summation of $H Q$. The HI of each co-ordinate areas were compared and illustrated by a GIS-based map. In the dry season, most areas were exposed to air pollution and $H I>1$ which indicated potential health risks. The hazard map identified from average HI in 2011-2015, indicated potential health risk areas in the dry season were Chiang Rai, Mae Hong Sorn, Phayao and Phrae.
\end{abstract}

Keywords: GIS, Health risk, Northern haze, Thailand.

\section{Introduction}

The Geographic Information System (GIS) is a tool that can analyze, manage and present data that are linked to geographical locations. GIS based models can be applied in a multi objective assessment related to air quality data to predict the outcome and identify the risk areas (Pilla and Broderick, 2015; Pope and $\mathrm{Wu}, 2014)$. The wild fire emissions in several regions were mapping and defined the potential risk locations as hot spots using air modeling and GIS (Youssouf et al., 2014; Chuvieco, et al., 2010). In this present work, the air pollution distribution and risk areas were interpolated and compared between two events with and without biomass burning. The investigated area, north Thailand, covered $85,852.40 \mathrm{~km}^{2}$ with valley topography surrounded by paddyfields and sandwiched in between mountain ranges.

\footnotetext{
* Postgraduate Student, Chulalongkorn University, Thailand.

${ }^{\dagger}$ Professor, Chulalongkorn University, Thailand.
} 
Table 1. The Annual Comparison between Frequency of Fire (Time) and the Impact Area (1 rai = 0.4 acre) in 8 Provinces, North Thailand

\begin{tabular}{|c|c|c|c|c|c|c|c|c|c|c|}
\hline \multirow{2}{*}{ Provinces } & \multicolumn{2}{|c|}{2011} & \multicolumn{2}{|c|}{2012} & \multicolumn{2}{|c|}{2013} & \multicolumn{2}{|c|}{2014} & \multicolumn{2}{|c|}{2015} \\
\hline & (time) & (rai) & (time) & (rai) & (time) & (rai) & (time) & (rai) & (time) & (rai) \\
\hline Chiang Rai & 31 & 85 & 181 & 922 & 98 & 690 & 91 & 905 & 147 & 1,130 \\
\hline Chiang Mai & 448 & 2,796 & 865 & 6,264 & 1,361 & 14,541 & 937 & 9,044 & 1,179 & 12,611 \\
\hline Nan & 2 & 8 & 29 & 311 & 123 & 1,260 & 88 & 972 & 78 & 934 \\
\hline Phayao & 39 & 165 & 76 & 317 & 38 & 194 & 36 & 327 & 62 & 429 \\
\hline Phrae & 42 & 227 & 158 & 1,470 & 147 & 1,011 & 111 & 927 & 140 & 1,004 \\
\hline MaeHongSon & 176 & 820 & 413 & 2,499 & 508 & 2,955 & 429 & 2,919 & 471 & 3,840 \\
\hline Lampang & 131 & 669 & 242 & 1,463 & 310 & 1,994 & 375 & 1,746 & 399 & 2,958 \\
\hline Lamphun & 162 & 943 & 219 & 1,557 & 166 & 1,449 & 238 & 1,959 & 297 & 3,552 \\
\hline Total & 1,031 & 5,713 & 2,183 & 1,4803 & 2,751 & 2,4094 & 2,305 & 18,799 & 2,773 & 26,458 \\
\hline
\end{tabular}


There were eight provinces, namely, Chiang Rai, Chiang Mai, Nan,Phayao, Phrae, Mae Hong Son, Lampang and Lamphun with population $5,672,168$. People living in this area could expose to air pollutants from the burning of agricultural wastes and natural bush fires. In the north of Thailand forest fires usually occur in the dry season from December to May. The frequent and extensive bushfires have increased annually from 2011 to 2015 , particularly in upper north of Thailand. The information of a number of times the fire occurred was compared and summarized in Table 1. The highest frequency of bushfires occurred in 2015 (FFCD, 2015).

Wildfires, biomass burning or vegetation fires have become more concerned in public health and ecosystems impacts. Emissions from biomass burning include large amount of gaseous compounds and particulate matters contributing to the air environment. The relative contribution of wildfire emissions to the global annual emissions is approximately 64\% primary organic carbon (POC), 32\% of black carbon (BC), $41 \%$ of carbon monoxide (CO) and $15 \%$ of nitrogen oxides (NOx). These pollutants can have short or long term health effects on the exposed populations (Youssouf et al., 2014; Viswanathan et al., 2006; Johnston et al., 2002). From previous reports, potential risk from air pollutions were found associated with visibility, noncarcinogenic effect, carcinogenic and mutagenic risk (Jinsart et al., 2014; Pungkhom and Jinsart, 2014; Vinitketkumnuen et al., 2002). In this study, we aim to identify the hazard areas effect from major emissions, $\mathrm{PM}_{10}, \mathrm{CO}$ and $\mathrm{NO}_{2}$. These pollutants were chosen as the main pollutants due to their health significance and their complete data set from ambient air monitoring stations. Pollution distribution and health risk area maps were interpolated and illustrated as hazard index map using GIS model.

\section{Methodology}

\section{Site Location \& Monitoring Station}

The eight provinces in the north of Thailand, namely, Chiang Rai, Chiang Mai, Nan, Phayao, Phrae, Mae Hong Son, Lampang and Lamphun with 10 monitoring stations were shown in Figure 1. Air quality data from 2011 to 2015 were obtained from Pollution Control Department. Air Pollutions were measured followed the standard methods, $\mathrm{PM}_{10}$ by Beta attenuator air sampling average 24 hours in $\mu \mathrm{g} / \mathrm{m}^{3}$, CO by Non-Dispersive Infrared Detection average 8 hours in ppm, $\mathrm{O}_{3}$ by Ultraviolet Absorption Photometry average 8 hours in ppb. Measurement methods were consistent among monitoring stations. 
Figure 1. Study Sites Location and Monitoring Stations: Natural Resources and Environment Office, Chiang Rai (NR), City Hall, Chiang Mai (CM), Yupparajwittayalai school, Chiang Mai (YM), Sob Pad Lampang (SL), Ta See,Lampang (TL),Natural Resources and Environment office, Mae Hong Son (NH), Natural Resources and Environment office, Lamphun (NP), Knowledge park, Phayao (KY), Meteorological, Phrae (MP), Muang Nan Municipality office, Nan $(M N)$

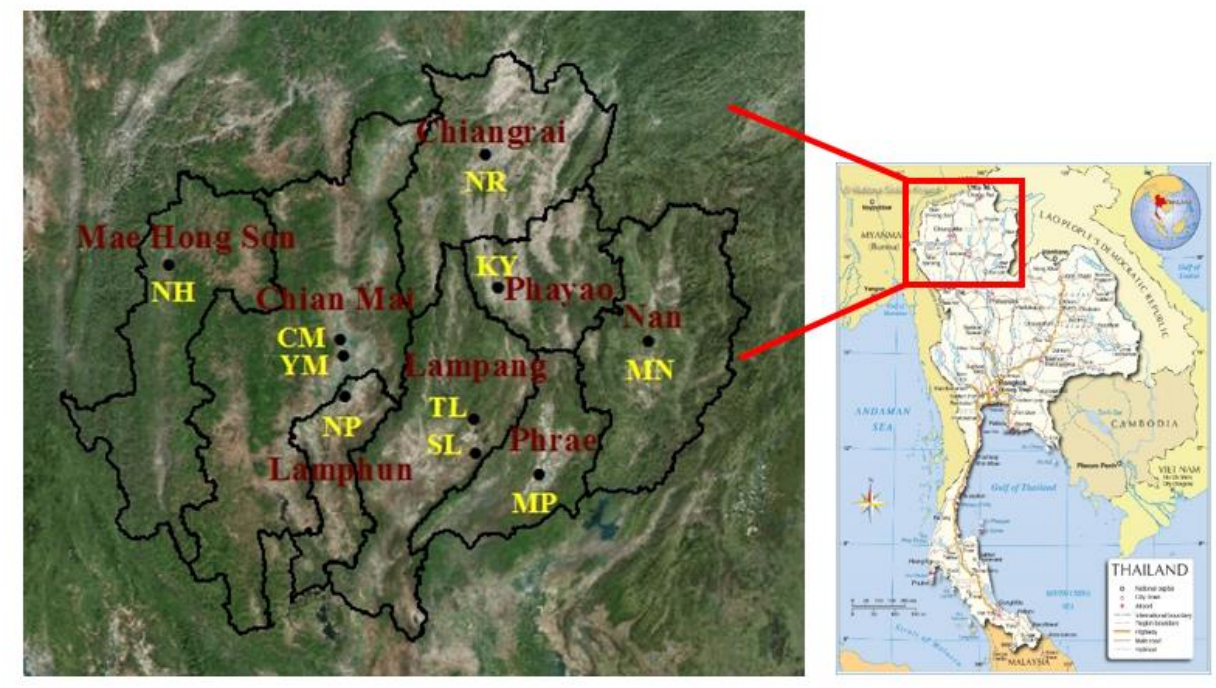

\section{Exposure Assessment}

The association between the health risk of pollutants exposed from the monthly incidence of haze pollutants were studied. Inhalation exposure concentrations, $\mathrm{EC}_{\mathrm{inh}}\left(\mu \mathrm{g} / \mathrm{m}^{3}\right)$ were calculated from ambient air quality data by equation1.

$$
\mathrm{EC}_{\mathrm{inh}}=\mathrm{C} \times \mathrm{ET} \times \mathrm{EF} \times \mathrm{ED} / \mathrm{AT} \quad \text { Equation } 1
$$

Where: C: concentration of each pollutants: $\mathrm{PM}_{10}, \mathrm{CO}$ and $\mathrm{O}_{3}\left(\mu \mathrm{g} / \mathrm{m}^{3}\right)$; ET: exposure time (24 hours/day); EF: exposure frequency (350 day/year); ED: exposure duration (30 years); AT: average time (for non-carcinogens, AT = ED in years $\times 365$ days $\times 24$ hours/day). All parameters used in the calculation $\mathrm{EC}_{\mathrm{inh}}$ were found in reports published by U.S. EPA (2009).

\section{Risk Characterization}

Risk Characterization ware separately quantified for non-carcinogenic effects. $\mathrm{PM}_{10}, \mathrm{CO}$ and $\mathrm{O}_{3}$ were evaluated by the hazard quotient (HQ), equation2.

$$
\mathrm{HQ}=\mathrm{EC} / \mathrm{RfC} \quad \text { Equation } 2
$$


Where: RfC is inhalation reference concentration; $\mathrm{CO}=2.3 \times 10^{1} \mathrm{mg} / \mathrm{m}^{3}$ $\mathrm{O}_{3}=1.8 \times 10^{-1} \mathrm{mg} / \mathrm{m}^{3}$ OEHHA (2014) (http://oehha.ca.gov/air/allrels.html); $\mathrm{PM}_{10}=50 \mu \mathrm{g} / \mathrm{m}^{3}$ WHO (2005).

The hazard index $(\mathrm{HI})$ is the summation of HQ, equation 3.

$$
\mathrm{HI}=\Sigma \mathrm{HQ} \quad \text { Equation } 3
$$

Where: HI is used to assess the overall potential for non-carcinogenic defects exposed by more than one chemical. HI below one indicates that there is no significant risk of non-carcinogenic effects. Conversely, if HI is more than one, there should be a risk of non-carcinogenic effects occurring, with a probability increase as the value of HI increases (U.S. EPA, 2013).

\section{Statistical Analysis}

For the monitoring data treatment, the Anova $(p<0.05)$ was applied to determine the statistical significance for the differences between the means of season variation. Fisher's Least Significant Difference (LSD) method is used in Anova to create confidence intervals for all pair wise differences between factor level means while controlling the individual error rate to a specific significance level. Therefore, LSD was used to test frequency of risk areas from year 2011 to 2015 .

\section{Geographic Information Systems}

$\mathrm{PM}_{10}, \mathrm{CO}$ and $\mathrm{O}_{3}$ concentration distribution and Hazard indices (HI) were mapping. To measure the distances, a geodesic calculator was used to convert Bath-Geo WGS84 projection coordinates (longitude/latitude) into the Universal Transverse Mercator (UTM) Zone 47(47N) (http://twcc.fr/). Spatial data of HI were prepared in the spread sheet before upload in the GIS map using the ArcGIS version 10.1. The spatial distributions of different variables were illustrated. The small variations of the pollutants concentrations in the study area were estimated. We used the Inverse Distance Weighted (IDW) interpolation method to estimate the hazard and self-maps illustration. Weights for sample values of each input points were normalized inverse of the distance from the control point to the interpolation point. It weights the points closer to the processing points more than those further away. A required number of points within a specified radius are used to determine the output value for each location (Thepanondh and Toruksa, 2011). 


\section{Results and Discussion}

\section{Data Treatment}

From Anova test, the ambient air pollution concentration among 10 stations was statistical significance different $(p<0.05)$ between the dry season and the wet season in 2011-2015. The results of the Least Significant Difference (LSD) analysis indicated that Mae Hong Sorn, Phayao and Phrae were high frequency risk areas.

\section{Air Pollution Distribution}

Biomass burnings frequently occurred in the dry season, thing which caused severe haze in the areas while in the wet season, haze was not found.The frequency and expansion of bush fire has been increasing each year. From Table 1, in 2013, 2014 and 2015 the fire events occurred 2,751, 2,350 and 2,773 times respectively (FFCD, 2015). Among three related biomass burning pollutants, $\mathrm{PM}_{10}, \mathrm{CO}$ and $\mathrm{O}_{3}, \mathrm{PM}_{10}$ were found as the major pollutants in all the sites. Particularly in the dry season, Jan-Apr, $\mathrm{PM}_{10}$ levels were higher than National Ambient Air Quality Standard $\left(120 \mu \mathrm{g} / \mathrm{m}^{3}\right)$. The comparison of the monthly average $\mathrm{PM}_{10}$ from 2011-2015 was shown in Figure 2 which was found in the same trend.

\section{Hazard Quotient (HQ)}

The exposure concentrations of $\mathrm{PM}_{10}, \mathrm{CO}$ and $\mathrm{O}_{3}$ were calculated from ambient air concentrations following the equation 1. Then HQs were calculated from the equation 2. For example, HQs of 10 monitoring sites in 2012 were compared in Table 2. All sites have $\mathrm{HQ}_{\mathrm{Co}}$ and $\mathrm{HQ}_{\mathrm{O} 3}<1$ which could mean no potential adverse health effects from $\mathrm{CO}$ and $\mathrm{O}_{3}$. The HQs of $\mathrm{PM}_{10}$ all sites in the dry season and long term annual HQ at MP and NR stations found HQ $>1$. These indicated potential health impacts from $\mathrm{PM}_{10}$ exposure that could harm the population in the areas. 
Table 2. HQs of $\mathrm{PM}_{10}, \mathrm{CO}$ and $\mathrm{O}_{3}$ Exposure in 2012

\begin{tabular}{|c|c|c|c|c|c|c|c|}
\hline \multirow[b]{2}{*}{ Pollutant } & \multirow[t]{2}{*}{ Station } & \multicolumn{2}{|c|}{ Dry Season } & \multicolumn{2}{|c|}{ Wet Season } & \multicolumn{2}{|c|}{ Annual } \\
\hline & & $\begin{array}{c}\mathrm{EC} \\
\left(\mu \mathrm{g} / \mathrm{m}^{3}\right)\end{array}$ & HQ & $\begin{array}{c}\mathrm{EC} \\
\left(\mu \mathrm{g} / \mathrm{m}^{3}\right)\end{array}$ & HQ & $\begin{array}{c}\mathrm{EC} \\
\left(\mu \mathrm{g} / \mathrm{m}^{3}\right)\end{array}$ & HQ \\
\hline \multirow{10}{*}{$\mathrm{PM}_{10}$} & SL & 78.89 & 1.58 & 26.27 & 0.53 & 46.78 & 0.94 \\
\hline & TL & 82.68 & 1.65 & 29.17 & 0.58 & 46.22 & 0.92 \\
\hline & $\mathrm{CM}$ & 71.51 & 1.43 & 23.42 & 0.47 & 41.34 & 0.83 \\
\hline & YM & 62.11 & 1.24 & 27.78 & 0.56 & 40.27 & 0.81 \\
\hline & NR & 94.91 & 1.90 & 23.37 & 0.47 & 50.66 & 1.01 \\
\hline & $\mathrm{NH}$ & 95.03 & 1.90 & 13.38 & 0.27 & 42.63 & 0.85 \\
\hline & $\mathrm{NP}$ & 84.10 & 1.68 & 20.14 & 0.40 & 44.28 & 0.89 \\
\hline & KY & 91.43 & 1.83 & 18.58 & 0.37 & 48.64 & 0.97 \\
\hline & MP & 90.11 & 1.80 & 25.32 & 0.51 & 51.72 & 1.03 \\
\hline & $\mathrm{MN}$ & 76.09 & 1.52 & 20.26 & 0.41 & 41.98 & 0.84 \\
\hline \multirow{10}{*}{$\mathrm{CO}$} & SL & 1.18 & 0.05 & 0.63 & 0.03 & 0.84 & 0.04 \\
\hline & $\mathrm{TL}$ & 0.52 & 0.02 & 0.27 & 0.01 & 0.37 & 0.02 \\
\hline & $\mathrm{CM}$ & 0.74 & 0.03 & 0.41 & 0.02 & 0.56 & 0.02 \\
\hline & YM & 1.21 & 0.05 & 0.58 & 0.03 & 0.80 & 0.03 \\
\hline & NR & 1.24 & 0.05 & 0.55 & 0.02 & 0.80 & 0.03 \\
\hline & $\mathrm{NH}$ & 1.10 & 0.05 & 0.41 & 0.02 & 0.68 & 0.03 \\
\hline & $\mathrm{NP}$ & 0.88 & 0.04 & 0.41 & 0.02 & 0.59 & 0.03 \\
\hline & KY & 0.63 & 0.03 & 0.36 & 0.02 & 0.47 & 0.02 \\
\hline & MP & 1.02 & 0.04 & 0.71 & 0.03 & 0.80 & 0.03 \\
\hline & $\mathrm{MN}$ & 0.88 & 0.04 & 0.36 & 0.02 & 0.53 & 0.02 \\
\hline \multirow{10}{*}{$\mathrm{O}_{3}$} & SL & 0.07 & 0.39 & 0.02 & 0.12 & 0.04 & 0.24 \\
\hline & TL & 0.06 & 0.31 & 0.02 & 0.09 & 0.03 & 0.18 \\
\hline & $\mathrm{CM}$ & 0.07 & 0.37 & 0.02 & 0.12 & 0.04 & 0.23 \\
\hline & YM & 0.05 & 0.30 & 0.02 & 0.13 & 0.04 & 0.21 \\
\hline & NR & 0.05 & 0.29 & 0.02 & 0.13 & 0.04 & 0.20 \\
\hline & $\mathrm{NH}$ & 0.05 & 0.25 & 0.02 & 0.09 & 0.03 & 0.16 \\
\hline & $\mathrm{NP}$ & 0.04 & 0.22 & 0.03 & 0.17 & 0.04 & 0.21 \\
\hline & KY & 0.07 & 0.40 & 0.03 & 0.16 & 0.05 & 0.27 \\
\hline & MP & 0.06 & 0.31 & 0.03 & 0.18 & 0.04 & 0.24 \\
\hline & MN & 0.06 & 0.33 & 0.03 & 0.14 & 0.04 & 0.21 \\
\hline
\end{tabular}


Figure 2. $P M_{10}$ Distributed in 2011-2015, Comparison Dry Season (January April) and Wet Season (July-October)

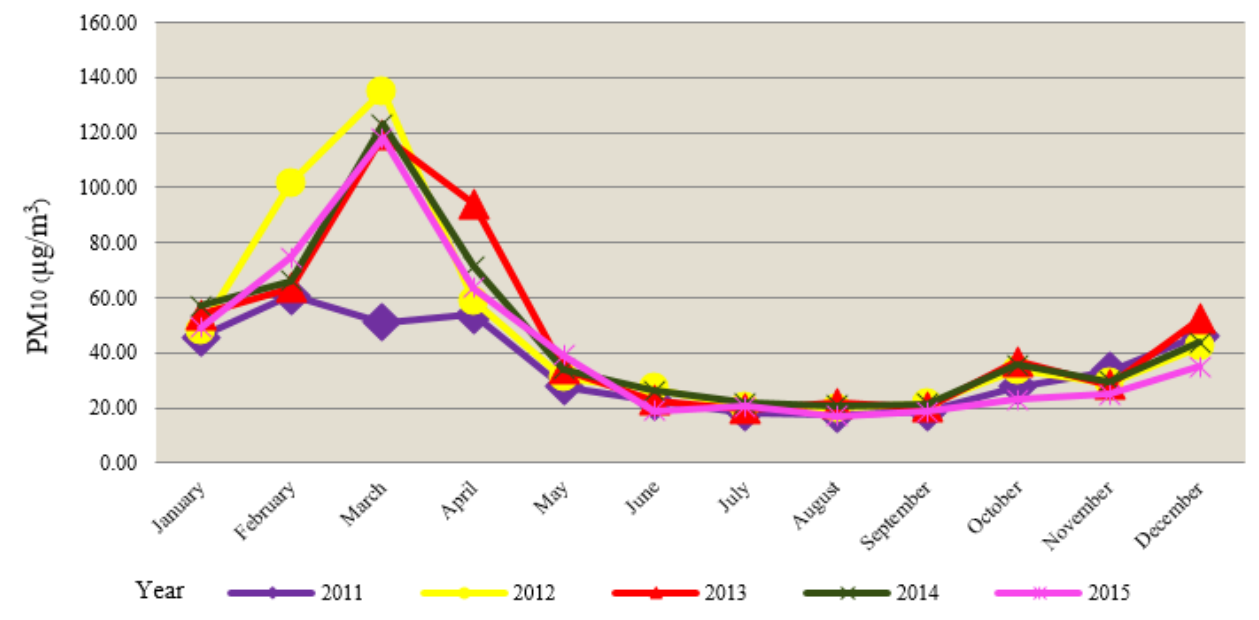

Hazard Index (HI)

Figure 3. Hazard Indices $\left(\mathrm{HI}_{P M 10, \mathrm{CO}, 03}\right)$ of the Eight Provinces, Sites Comparison during Dry Season and Wet Season in 2011-2015

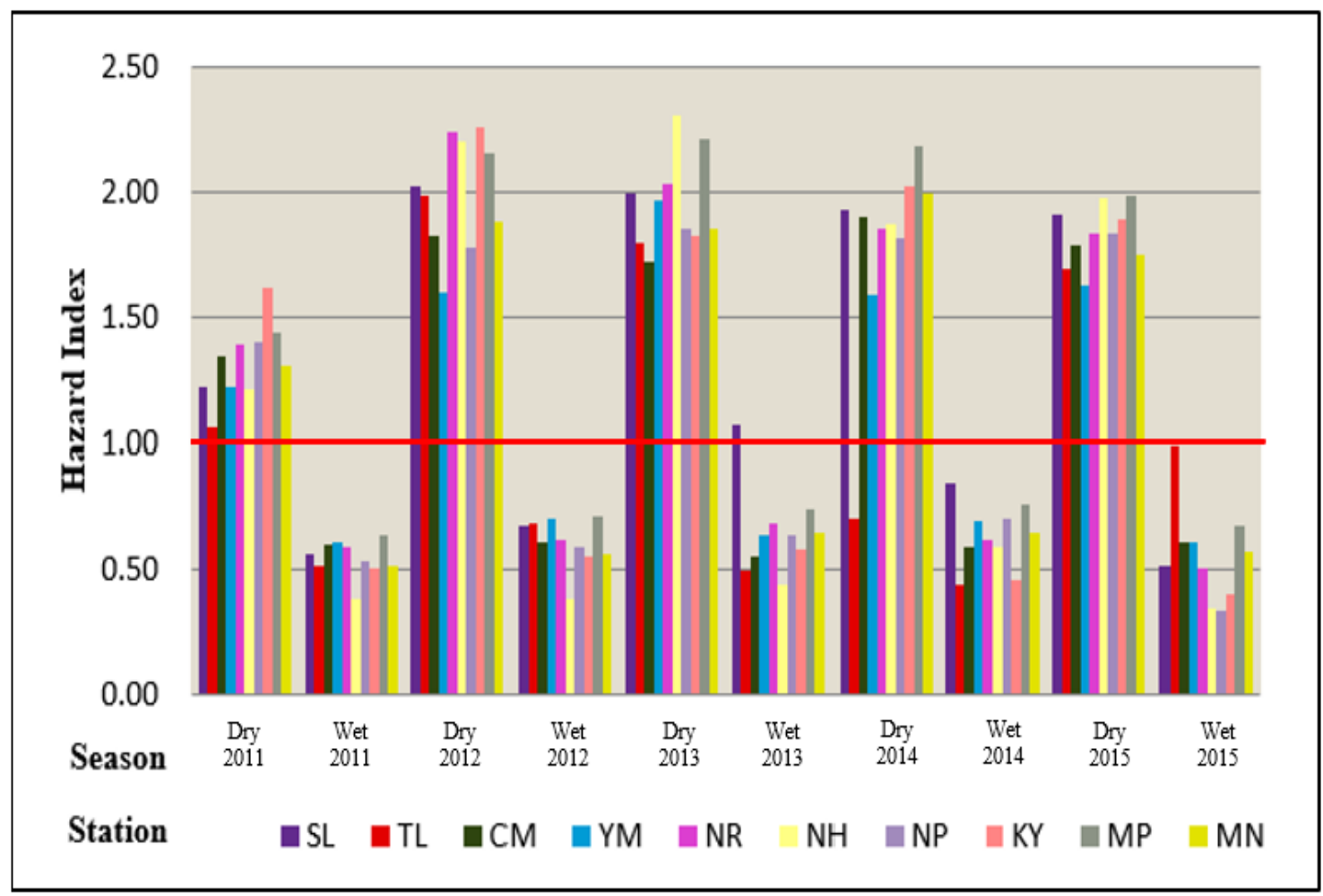




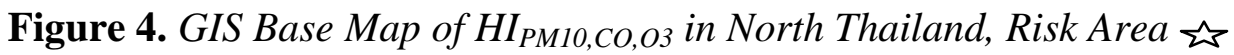
(A) 2011 Dry Season, (B) 2012 Dry Season, (C) 2013 Dry Season, (D) 2014 Dry Season, (E) 2015 Dry Season, $(F) 2015$ Wet Season

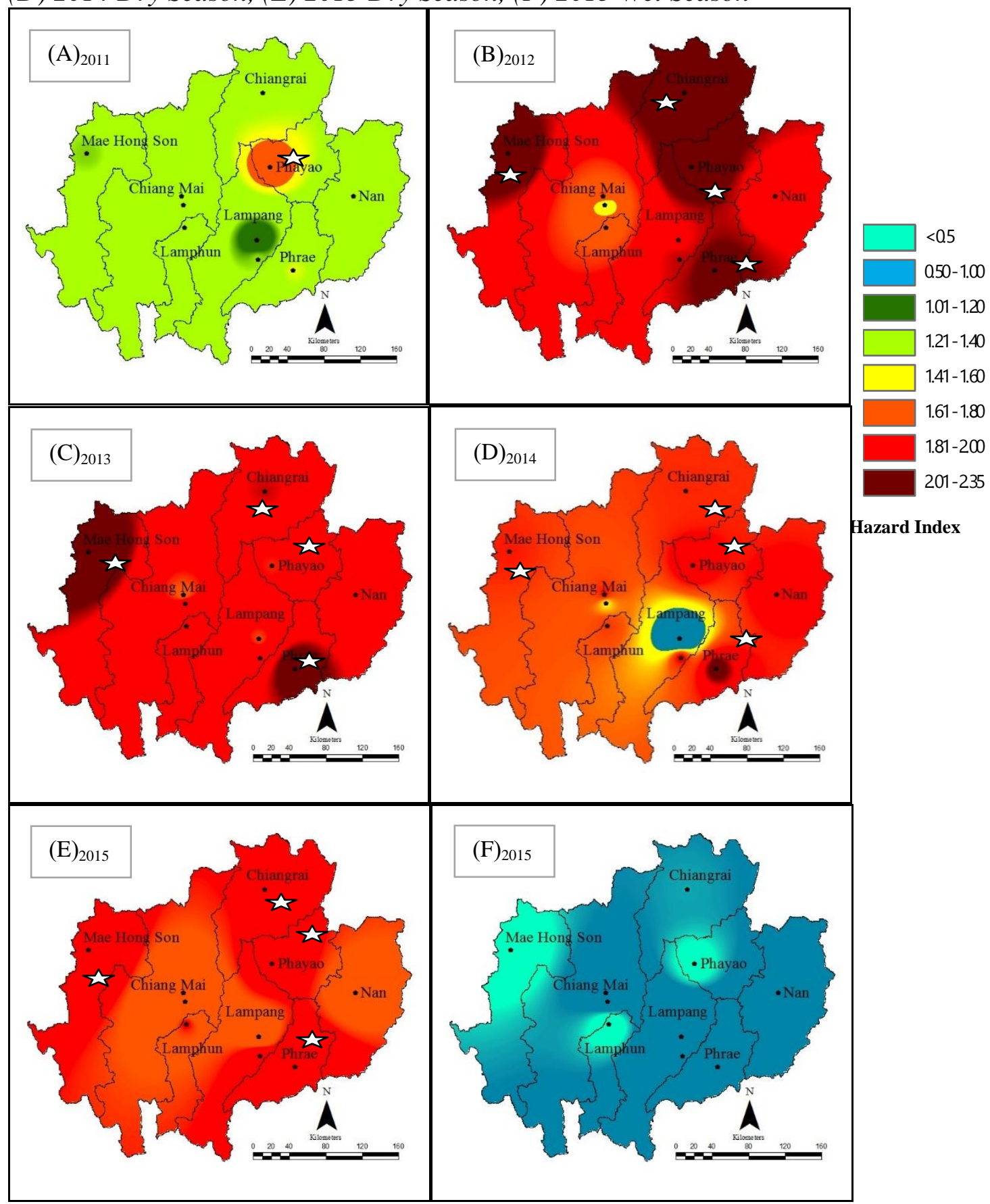

The hazard index (HI) of short term and long term exposures were calculated from equation 3. HI and related areas were summarized in Figure 3. For the short term in Non-Haze wet season, HI was lower than 1 at all sites but in the dry season HI was higher than 1. The risk areas were identified by different $\mathrm{HI}$ and the impact sites were illustrated by GIS-based maps in Figure 
4. Health risk areas in north Thailand were identified by province and site locations. In the dry season, there was potential risk from exposure of high level of pollutions, particularly $\mathrm{PM}_{10}$. HI of all sites was more than 1 which indicated potential health risk. Most hazard areas were varied such as in 2011 at Phayao (KY); in 2012 at Chiang Rai (NR), Mae Hong Sorn (NH), Phayao (KY) and Phrae (MP); in 2013 at Mae Hong Sorn (NH), and Phrae (MP); in 2014 at Phrae (MP) and in 2015 at Chiang Rai (NR), Mae Hong Sorn (NH), Phayao (KY) and Phrae (MP). From both hazard map and average HI in 2011-2015, four high risk provinces were located in Chiang Rai (NR), Mae Hong Sorn (NH), Phayao (KY) and Phrae (MP), Figures 3 and 4.

However, when compared between land use data and the hazard areas, from 2008-2015, Table 3, agriculture areas in all eight provinces were increasing (LDD, 2015). This could induce more biomass burning from agriculture wastes and spread to the wild land. Among 8 provinces in comparison, largest agriculture areas were covered in Chiang Rai, 3,551,846 rai. While in Phrae, agriculture areas was found highest increasing from $22 \%$ to $28 \%$ increased 725180 rai ( 1 rai $=0.4$ acre). Although in Mae Hong Sorn, the vegetation areas were not much increased, only 216,604 rai but there was continuous increasing of wildfire areas as shown in Table 1 . Therefore the wildfire emissions were dominant in this province including the pollutants transported from the border line. In the case of, Phayao had increasing land use for agriculture 158,440 rai, Table 3 but showed high level of air pollutions and $\mathrm{HI}$ which implied that some other source emissions from new urbanization areas were contributed to this high risk zone. The further monitoring and pollution prevention policy was recommended for Chiang Rai, Phrae, MaeHongSorn and Phayao.

Table 3. Land Use Data of Agriculture Area (rai) and Percentage \% Compared to Total Province Area in North Thailand, Data were Summarized from Two Groups of Survey Year Duration in 2008-2010 and 2012-2015 (2011 No Data)

\begin{tabular}{cccccc}
\hline & \multicolumn{4}{c}{ Land Use: agriculture areas (1 rai=0.4 acre) } \\
Years & \multicolumn{2}{c}{ Years } & Increasing \\
Province & $2008-2010$ & \multicolumn{2}{c}{$2013-2015$} & Rai \\
& Rai & $\%$ & Rai & $\%$ & 334,233 \\
Chiang Rai & $3,217,613$ & 44.07 & $3,551,846$ & 48.66 & 227,529 \\
Chiang Mai & $2,777,253$ & 22.02 & $3,004,782$ & 23.91 & 508,521 \\
Nan & $1,912,265$ & 26.67 & $2,420,786$ & 33.76 & 158,440 \\
Phayao & $1,430,728$ & 36.14 & $1,589,168$ & 40.1 & 725,180 \\
Phrae & 890,881 & 21.79 & $1,616,061$ & 28.41 & 216,604 \\
MaeHongSon & $1,168,741$ & 14.76 & $1,385,345$ & 17.48 & 379,565 \\
Lampang & $1,311,388$ & 16.74 & $1,690,953$ & 21.56 & 67,777 \\
Lamphun & 797,199 & 28.31 & 864,976 & 30.7 & \\
\hline Source: http://www.ldd.go.th/web_OLP/report_research_N.html \#north.
\end{tabular}




\section{Conclusions}

The HI's of each of the co-ordinate areas were compared and illustrated by a GIS-based map. The association between exposure concentration and risk areas were compared. In the dry season, HI of eight provinces was more than 1 which indicated potential health risk. From hazard map and average HI, three high risk provinces in the north Thailand were Mae Hong Sorn, Phayao and Phrae.

\section{Acknowledgments}

This study was partially funded by the Environmental research and training centre, Ministry of national resources and environment Thailand in 2015. The authors are grateful for valuable suggestions in GIS from Prof. Dr. Chalermchon Sathirapod, Department of Survey, Faculty of Engineering, Chulalongkorn University. We are deeply appreciated the monitoring information from Pollution Control Department and Department of forest fire management Thailand.

\section{References}

Chuvieco, E., Aguado, I., Yebra, M., Nieto, H., Salas, J., Martin, M.P., Vilar, L., Martinez, J., Martin, S., Ibarra, P., Riva, J.D.L., Baeza, J., Rodriguez, F., Molina, J.R., Herrera, M.A. and Zamora, R. 2010. Development of a framework for fire risk assessment using remote sensing and geographic information system technologies. Ecological Modelling 221, (2010), 46-58.

FFCD-Forest Fire Control Division National Park, 2015. Forest fire statistics. http://www.dnp.go.th/forestfire/2546/firestatistic\%20Th.htm.

Jinsart, W., Arbmanee, D., Ngeabprasert, R. and Pungkhom, P., 2014. Impact on Visibility and Air Quality from Bushfire Smog in Northern Thailand, A\&WMA's 2014 Navigating Environmental Crossroads, June 24-27, (2014), Long Beach, CA, USA.

Johnston, F.H.; Kavanagh, A.M.; Bowman, D.M. and Scott, R K. 2002. Exposure to Bushfire smoke and asthma: an ecological study. Medical Journal of Australia, 176, (2002), 535-538.

Land Development Department (LDD), 2015. http://www.ldd.go.th/web_OLP/report_ research_N.html\#north.

OEHHA, 2014. OEHHA Acute, 8-hour and Chronic Reference Exposure Level (REL) as of June 2014. http://oehha.ca.gov/air/allrels.html.

Pilla F and Broderick B., 2015. A GIS model for personal exposure to $\mathrm{PM}_{10}$ for Dublin commuters. Sustainable Cities and Society, 15 (2015), 1-10.

Pope R. and Wu J., 2014. A multi-objective assessment of an air quality monitoring network using environmental, economic, and social indicators and GIS-based model.JAWMA,64(6), (2014), 721-737.

Pungkhom, P. and Jinsart, W., 2014. "Health Risk Assessment from bush fire air pollutants using statistical analysis and Geographic Information System: case 
study in the northern Thailand" International Journal of Geoinformatics, 10(1), (2014), 17-24.

Thepanondh, S. and Toruksa, W. 2011. Proximity analysis of air pollution exposure and its potential risk. J. Environ. Monit. 13, (2011), 1264-1270.

U.S. EPA, 2009. Risk Assessment Guidance for superfund in part F, Supplemental Guidance for Inhalation Risk Assessment., vol.1, http://bit.ly/2cchzb6.

U.S. EPA, 2013. Human Health Risk Assessment., http://bit.ly/2c3fznR.

Vinitketkumnuen U., Kalayanamitra K.,Chewonarin T. and Kamens R., 2002 Particulate matter, $\mathrm{PM}_{10} \& \mathrm{PM}_{2.5}$ levels, and airborne mutagenicity in Chiang Mai Thailand. Mutation Research, 519, (2002), 121-131.

Viswanathan S., Eria L., Diunugala N., Johnson J. and McClean C., 2006. An analysis of effects of San Diego Wildfire on ambient air quality. JAWMA, 56, (2006), 56-67.

WHO, 2005. Air quality guidelines for particulate matter, ozone, nitrogen dioxide and sulfur dioxide, http://bit.ly/2cJHoTN.

Youssouf H., Liousse C., Roblou L., Assamoi E.M., Salonen R.O., Maesano C., Banerjee S.,and Annesi-Maesano I., 2014. Quantifying wildfires exposure for investigating health-related effects. Atmospheric Environment, 97, (2014), 239-25. 